\title{
Auf ein Wort
}

Mag. Martin Peithner

MBA, Geschäftsführer der Austroplant Arzneimittel GmbH

sowie der Dr. Peithner KG, nunmehr G.m.b.H. \& Co.,

im Gespräch mit Dr. Renate Höhl

Wie sieht Ihre Produktpalette 2009 aus?

Mit mehr als 2.200 Produkten ist die Palette der beiden Unternehmen natürlich einem ständigen Wandel unterlegen. Das Jahr 2009 steht dennoch im Zeichen von mehreren wichtigen Produkteinführungen. Auf Seiten der Dr. Peithner KG kamen Anfang des Jahres zwei homöopathische Ohrentropfen, Otodolor ${ }^{\circledR}$ und Otodolor forte ${ }^{\circledR}$, auf den Markt. Im April folgte eine Line-extension für die bewährten Gracil-Schlankheitstropfen ${ }^{\circledR}$ in Form von Tabletten. Anfang Juni folgt die Markteinführung von Travelex ${ }^{\circledast}$, einem homöopathischen Kaugummi bei Reiseübelkeit.

Bei der Austroplant steht im Herbst die Einführung von Vitango ${ }^{\circledR}$ auf dem Plan. Vitango ${ }^{\circledR}$ ist ein traditionelles pflanzliches Arzneimittel zur Behandlung von Stress und gleichzeitig das erste Produkt der Schwabe-Gruppe, welches europaweit nahezu zeitgleich und mit einheitlichem Auftritt gelauncht wird.

Welchen Stellenwert haben Homöopathika, welchen Phytopharmaka in der heutigen Medizin?

Pflanzliche Arzneimittel sind schon immer ein wichtiger Teil des Arzneischatzes gewesen. Dies hat sich auch nicht sehr verändert, obwohl bedauerlicherweise immer

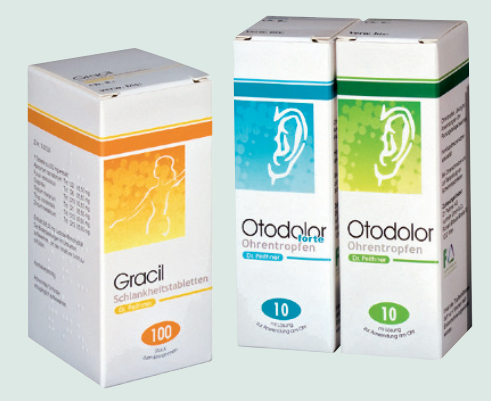

mehr pflanzliche Produkte aus der Erstattung durch die Krankenkassen herausfallen. Dies ist insbesonders deshalb nicht sinnvoll, da pflanzliche Produkte in ihrer Wirksamkeit den chemisch-synthetischen meist gar nicht oder nur minimal unterlegen sind, meistens jedoch ein deutlich günstigeres Profil bei den Wechselund Nebenwirkungen zeigen.

Darüber hinaus sind die pflanzlichen Produkte auch preisgünstiger als ihre chemisch-synthetischen Mitbewerber. Die Ursache liegt darin, dass die Aufnahmekriterien des Hauptverbandes Unterlagen und Studien verlangen, die weit über die offiziellen Zulassungsanforderungen hinausgehen und von den überwiegend kleineren und mittelgroßen Unternehmen, welche pflanzliche Produkte herstellen und vertreiben, aus Kostengründen nicht vorgelegt werden können.

Wie uns regelmäßige Umfragen durch das GfK-Institut zeigen, wird auch die Homöopathie in der Bevölkerung heute als integrierter Bestandteil der Medizin gesehen. Die „Glaubenskriege" der 70er- und 80er-Jahre des letzten Jahrhunderts werden heute nur mehr durch einige wenige radikale Kliniker künstlich am Leben erhalten, während sich bei der breiten Masse der Ärzte und Patienten ein sehr ausgewogenes Miteinander dieser unterschiedlichen Therapierichtungen etabliert hat.

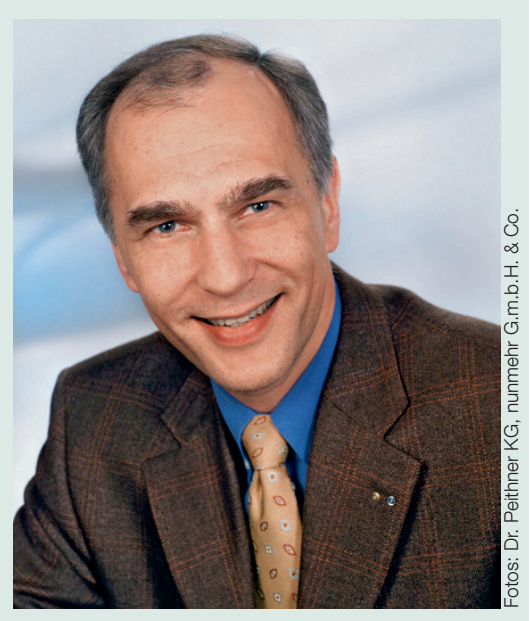

Welche Rolle kommt Ihrer Firma heute zu, und welche Veränderungen stehen für die Zukunft an? Die Unternehmensgruppe Dr. Peithner KG/Austroplant $\mathrm{GmbH}$ ist schon seit vielen Jahren unangefochtener Marktführer bei den pflanzlichen und homöopathischen Arzneimitteln.

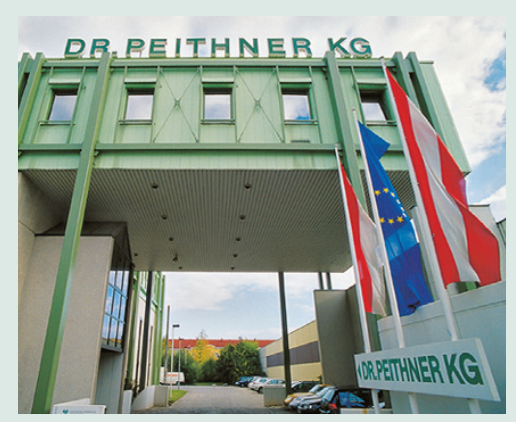

Die größte Veränderung der Unternehmensgeschichte haben wir rund um Ostern erlebt, als die gesamte Unternehmensgruppe Dr. Peithner an unseren langjährigen Partner die Dr. Willmar Schwabe International $\mathrm{GmbH}$ verkauft wurde. Im operativen und personellen Bereich ändert sich dadurch gar nichts, jedoch sind wir durch diesen Zusammenschluss sehr viel besser für die Herausforderungen der Zukunft gerüstet.

Wie sich inzwischen auch herausstellte, wird unserer guten Arbeit in der Vergangenheit auch dadurch Rechnung getragen, dass die Produktion am Standort Wien erheblich ausgeweitet wird und wir zu einem wichtigen Produktionsstandort im Firmenverbund Schwabe werden.

\section{Vielen Dank!}

